colleagues noted in a comprehensive review of best practices (www.uleth .ca/dspace/handle/10133/3121). These include reducing the number of venues, eliminating the highest-risk forms of gambling, constraining maximum bet amounts, requiring gamblers to precommit to daily expenditure limits, asking all patrons for identification to enforce self-exclusion lists and restricting access to alcohol and automated banking machines in casinos.

European countries tend to have far stricter policies, notes Williams, and, as a result, their problem-gambling rates are only a fraction of those in Canada. Some practices allowed by provincial governments, such as providing gamblers with rewards if they spend more, may actually be contributing to problem gambling. "These things don't make any sense," says Williams. "Canadians would never accept being rewarded for alcohol consumption, but we do that for gambling."

Because provincial policies are limited, problem gamblers continue to con- tribute a disproportionate amount to gaming revenues. A 2011 report for the Alberta Gambling Research Institute prepared by Williams and colleagues indicated that problem gamblers are responsible for about $50 \%$ of gambling expenditures in Alberta, and account for an even higher rate of money swallowed by slot machines and video lottery terminals. (http://research.uleth.ca/seiga/seiga _final_report.pdf).

Reducing problem gambling might reduce revenues, but it would do wonders to improve the lives of not only those addicted to gambling, but also those of employees in casinos and other gambling venues, suggests Robert Murray, manager of the Problem Gambling Project at the Centre for Addiction and Mental Health in Toronto, Ontario.

"That is probably the most difficult aspect of working in this industry, having family members pounding on the door and yelling 'Get my husband out of there,"' says Murray. "Everyone wants to feel that they work in an environment that takes care of their customers."
Though there is still much room for progress in reducing problem gambling, the industry does appear more open to intervening now than in the past, says Murray. The Centre for Addiction and Mental Health has worked with people employed in the gambling industry to help them identify when and how to intervene.

"We are not trying to train them to be clinicians or to diagnose a gambling problem, but there are hundreds of thousands of people walking through the doors of casinos every day, and those employees are going to be dealing with problems whether or not they have training," says Murray. "We equip them with certain basic communication skills and an understanding of how to positively engage people, and how to link the customer to available resources should they need that." Roger Collier, CMAJ

A longer version of this article is available at cmaj.ca

CMAJ 2013. DOI:10.1503/cmaj.109-4503

\title{
Drug reporting may be mandatory for doctors
}

$\mathrm{T}$ he federal government is considering making adverse drug reaction reporting mandatory for doctors and other health care providers.

Only 5\% of suspected adverse drug reactions (ADRs) are now reported according to an estimate from the Senate Committee on Social Affairs, Science and Technology.

Underreporting reduces Health Canada's ability to rapidly detect safety problems related to drugs or medical devices and to change labelling, warnings and advisories, Health Canada senior media officer Leslie Meerburg wrote in an email.

Health Canada will "take concrete action" to improve its ADR reporting system, said Health Minister Leona Aglukkaq.

ADR reporting is currently voluntary for everyone except pharmaceutical manufacturers and distributors. The latter two must submit all Canadian ADR reports and serious international reports to the federal government's Canada Vigilance program. The reports are analyzed and if a problem is found, health care providers and the public are informed, and drug packaging may be changed or the drug taken off the market.

However, this process can take up to two years, states the Senate Report on Post-Approval Monitoring of Pharmaceuticals, released Mar. 26. The report also criticized Health Canada for not paying enough attention to international ADR reports; in a nation with a relatively small population, these reports provide valuable information.

Health Canada is also considering making reporting mandatory for doctors, which will flood the system with data, says Dr. Eric Wooltorton, assistant family medicine professor at Ottawa University, Ontario. And more doesn't necessary mean better quality, he says. What's really needed is a better system to interpret the reports.

"The issue is not just getting doctors to report," adds Dr. David Healy,

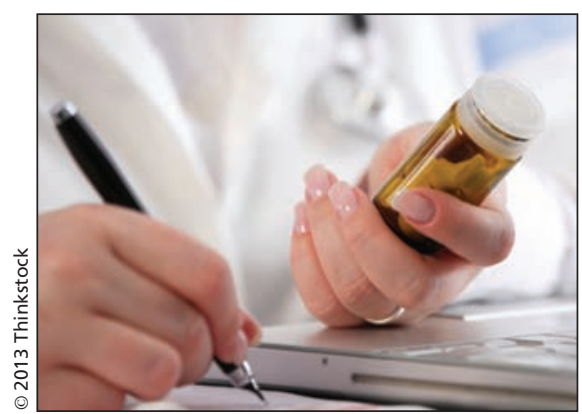

If drug reporting becomes mandatory for doctors, the system will be flooded with data.

founder and CEO of RxISK, a website where patients can report ADRs and health care providers can research medications. "The issue is having a person who's going to make sense of what the reports mean. Regulators aren't rained for this."

Health Canada needs to overhaul the way reports are interpreted and acted upon, he says. - Catherine Cross, CMAJ

CMAJ 2013. DOI:10.1503/cmaj.109-4487 